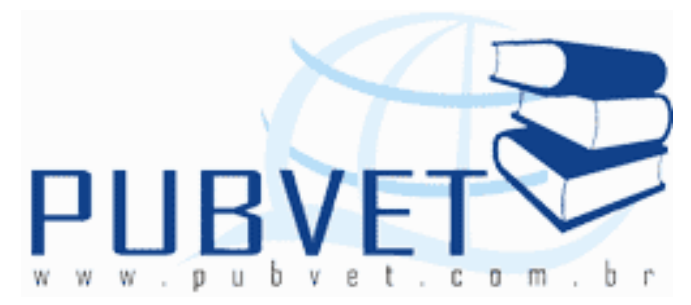

PUBVET, Publicações em Medicina Veterinária e Zootecnia.

\title{
Desenvolvimento alométrico em uma nova linhagem de codornas para corte
}

Janaína Scaglioni Reis ${ }^{1}$; Nelson José Laurino Dionello ${ }^{2}$; Aline Piccini Roll ${ }^{1}$, Victor Buttow Roll ${ }^{3}$; Aiane Aparecida da Silva Catalan ${ }^{1}$; Débora Cristina Nichelle Lopes $^{4}$; Ariane Gottuzo ${ }^{5}$

${ }^{1}$ Doutoranda do Programa de Pós-Graduação em Zootecnia da Universidade Federal de Pelotas

${ }^{2}$ Professor Associado 3 do Departamento de Zootecnia da Universidade Federal de Pelotas/Bolsista de Produtividade 2/CNPq

${ }^{3}$ Professor Adjunto do Departamento de Zootecnia da Universidade Federal de Pelotas

4 Professora Assistente do Curso de Medicina Veterinária da Universidade Federal do Pampa

5 Mestranda do Programa de Pós-Graduação em Zootecnia da Universidade Federal de Pelotas

\section{Resumo}

Objetivou-se avaliar a alometria das características de uma nova linhagem para codornas de corte em desenvolvimento no Departamento de Zootecnia da Universidade Federal de Pelotas. Foi utilizado um total de 120 aves, sendo 60 machos e 60 fêmeas em quatro idades de abate (35, 42, 49 e 56 dias). As análises para obtenção dos coeficientes alométricos foram realizadas através 
do procedimento GLM do SAS (2008). Não houve diferenças significativas para a maioria das variáveis estudadas, apenas ocorrendo diferença significativa no desenvolvimento alométrico para o crescimento do osso do peito e da asa para os machos na idade de 35 dias, os quais apresentaram desenvolvimentos precoces. Igualmente houve diferença significativa para gordura abdominal nos machos aos 56 dias sendo o desenvolvimento considerado tardio com crescimento heterogônio. Preconiza-se um abate mais precoce em codornas machos do tipo carne, evitando a deposição de gordura, o que acarreta custos desnecessários à produção dessas aves.

Palavras-chave: alometria, carcaça, desenvolvimento de tecidos, produção animal, seleção genética

\title{
Allometric development in a new type of meat quail
}

\begin{abstract}
The goal of this study was to evaluate allometric traits of a new type of meat quails which has been developed at Department of Animal Science of Universidade Federal de Pelotas. A total of 120 experimental units, 60 of each gender in four different slaughtering ages (35, 42, 49 and 56 days) were utilized. The statistical analysis was conducted using the GLM procedure of SAS. There were no significant differences between most of the variables studied. However, a significant difference in the allometric development was verified for the growth of breast bone and wing bone for 35-day males, which presented premature development. Likewise, there was significant difference in 56-day males' fat, which had late development with heterogonic growth. If one advocates slaughter earlier in the male meat quail, preventing the deposition of fat, which results in unnecessary costs to the production of these quail.
\end{abstract}

Keywords: allometry, animal production, carcass, genetic selection, tissues development 
REIS, J.S. et al. Desenvolvimento alométrico em uma nova linhagem de codornas para corte. PUBVET, Londrina, V. 6, N. 17, Ed. 204, Art. 1367, 2012.

\section{INTRODUÇÃO}

Dentro do processo de melhoramento genético de codornas de corte, a carcaça se constitui no principal produto comercializável, assim como em outros animais destinados a produção de carne. O desenvolvimento do corpo animal pode ser descrito pelo coeficiente de alometria, que permite estabelecer o tipo de carcaça ideal. Esta carcaça seria aquela com a máxima quantidade de tecido muscular, a mínima de tecido ósseo e a adequada deposição de gordura exigida pelo mercado ao qual será destinada, já que este método explica parte das diferenças quantitativas que se produzem entre animais e constitui um meio eficaz para o estudo das carcaças (SANTOS et al., 2001), que deverão apresentar aroma, suculência e sabor o que servirá de atributos para aceitação no mercado (MARTINS et al., 2008), especialmente em carne de codornas (MURAKAMI et al., 2008, OLIVEIRA et al., 2005) e carne de codorna mecanicamente separada (SOUZA et al., 2008).

Neste sentido é importante que estejam disponíveis para produtores e pesquisadores métodos rápidos e econômicos para estimar a composição física da carcaça e de seus cortes (SANTOS et al., 2009). Existem vários métodos de se medir o desenvolvimento corporal e alguns modelos e fórmulas foram indicados por diversos autores. Dentre estas a equação alométrica proporciona uma interessante descrição quantitativa da relação parte/todo e, mesmo não registrando detalhes, é interessante porque reduz toda a informação em um só valor (BERG et al., 1978). A equação alométrica mais utilizada foi a proposta por Huxley (1932), e é definida como $y=a x^{b}$.

A alometria para Cabrero (1984) explica parte das diferenças quantitativas que se produzem entre animais e constitui um meio eficaz para o estudo de suas carcaças. Na composição da carcaça, os tecidos muscular, ósseo e adiposo não se desenvolvem de forma isométrica, cada um terá impulso de crescimento diferente em uma fase da vida do animal (FORREST et al., 1979). A idade e o peso em que ocorrem a aceleração ou desaceleração no desenvolvimento de cada tecido dependem da raça, do sexo, do nível 
REIS, J.S. et al. Desenvolvimento alométrico em uma nova linhagem de codornas para corte. PUBVET, Londrina, V. 6, N. 17, Ed. 204, Art. 1367, 2012.

nutricional e do sistema de criação, entre outros fatores (SANTOS et al., 2001; ROTA et al., 2002)

Uma maior relação músculo:osso e uma menor relação músculo:gordura é de extrema importância do ponto de vista do consumidor, pois o músculo é o tecido mais valorizado da carcaça, sendo tal relação observada nas raças mais especializadas na produção de carne, de maior porte e mais tardias (OLIVEIRA et al.,1998; PEREIRA et al., 2001; OSÓRIO et al., 2002).

O conhecimento da quantidade dos diferentes tecidos que compõem a carcaça é de grande importância, pois pode proporcionar ao produtor uma melhor remuneração na venda dos animais (OSÓRIO et al., 1998). Segundo Santos (1999), a alometria, ao explicar parte das diferenças quantitativas entre os animais, pode ser um parâmetro eficaz no estudo da carcaça e de seus componentes.

De acordo com Ávila e Osório (1996), o estudo da alometria está baseado, principalmente, no fato de o desenvolvimento corporal ser uma função do peso e não do tempo necessário para alcançá-lo. Por isso, o abate de animais com determinada amplitude de variação de peso vivo, realizado seqüencialmente, tem sido um dos métodos mais utilizados para descrever o crescimento relativo dos componentes da carcaça (BERG e BUTTERFIELD, 1966).

A composição regional é realizada para determinar a proporção de cada parte dentro de uma carcaça, pois um dos critérios de qualidade é a porcentagem dos cortes de qualidade superior que a carcaça contém (SAÑUDO, 1980 ; LOPEZ, 1987).

Sendo assim objetivou-se analisar o desenvolvimento alométrico em codornas de corte machos e fêmeas, abatidas aos 35, 42, 49 e 56 dias de idade. 


\section{MATERIAL E MÉTODOS}

O experimento de campo foi realizado no Laboratório de Ensino e Experimentação Zootécnica Prof. Dr. Renato Peixoto (LEEZO), o abate das aves foi realizado no Conjunto Agrotécnico Visconde da Graça (CAVG) e a parte da dissecação foi realizada no Laboratório de Carnes do Departamento de Zootecnia da Universidade Federal de Pelotas.

Um total de 400 aves de uma nova linhagem de codornas de corte selecionadas pelo peso corporal aos 21 dias de idade, foram criadas em box com piso de concreto e cama de maravalha, com aquecimento a gás. Elas receberam água e ração à vontade. A alimentação foi a mesma para todas as codornas e em todas as fases, contendo $28 \%$ de proteína bruta e $2.900 \mathrm{Kcal}$ de energia metabolizável por $\mathrm{kg}$ de ração. Todas as aves foram alojadas em boxes de $2 \times 1 \mathrm{~m}$ com cama de maravalha. No galpão onde estão localizados os boxes $2 \times 1 \mathrm{~m}$ foram alojadas 20 codornas por boxe, totalizando 20 boxes e 400 animais, todas aves tiveram acesso a água e ração a vontade. A temperatura foi monitorada com auxílio de um termômetro visando o bem-estar das aves, como o experimento foi conduzido no inverno se utilizou de campânulas de gás para aquecimento e utilizando-se de controle de janelas para aeração. A umidade do ar foi equivalente a umidade da região do experimento, por volta de 70 a $80 \%$. O fotoperíodo que as aves foram submetidas foi de 16 horas de luz e 8 horas de escuro. As codornas foram selecionadas por peso aos 35, 42, 49 e 56 dias.

Como houve abate das aves foi necessário a aprovação pelo comitê de ética e experimentação animal (CEEA) da Universidade Federal de Pelotas cujo registro de aprovação é 5648.

Para o estudo da alometria foram abatidas 15 aves machos e fêmeas aos 35, 42, 49 e 56 para as análises alométricas, totalizando 120 aves. As aves foram pesadas para obtenção do peso vivo, abatidas e pesadas (peso carcaça) e congeladas (peso de carcaça fria). Após descongelamento foram separadas as partes em músculo e osso do peito, músculo e osso da perna, dorso, asa, 
REIS, J.S. et al. Desenvolvimento alométrico em uma nova linhagem de codornas para corte. PUBVET, Londrina, V. 6, N. 17, Ed. 204, Art. 1367, 2012.

pele, gordura abdominal e outros (fáscias, vasos sanguíneos e tecido conjuntivo). O estudo do crescimento relativo dos cortes foi realizado mediante o modelo da equação exponencial $Y=a X^{b}$, transformada logaritmicamente em um modelo linear, In $Y=\ln a+b \ln X$ (HUXLEY, 1932), em que $Y$ é o peso de cada componente corporal (músculo e osso do peito e da perna, asa e gordura abdominal); $\mathrm{X}$, o peso da carcaça fria (PCF); a, o intercepto do logaritmo da regressão linear sobre $Y$ e "b" e b, o coeficiente de crescimento relativo ou coeficiente de alometria.

As análises para obtenção dos coeficientes alométricos foram realizadas através do procedimento GLM do Programa SAS (2008). Para verificação da hipótese $b=1$, foi realizado o teste "t" (Student) $(p<0,05)$, para as diferentes idades de abate, dentro de cada sexo.

Quando ocorreu 0 valor de $b=1$ (teste " $t$ " não significativo), 0 crescimento foi denominado isogônico, indicando que as taxas de desenvolvimento de " $\mathrm{X}$ " e "Y" foram semelhantes no intervalo de crescimento considerado. Quando $b \neq 1$ (teste " $t$ " significativo), o crescimento foi considerado heterogônico, e quando positivo ( $b>1$ ), o órgão foi considerado de desenvolvimento tardio e quando negativo $(b<1)$, o órgão apresentou-se de desenvolvimento precoce.

\section{RESULTADOS E DISCUSSÕES}

Os resultados apresentados nas Tabela 1 e 2 mostram que houve diferença significativa no desenvolvimento alométrico para o desenvolvimento do osso do peito $(P=0,05)$ e da asa $(P=0,02)$ para os machos na idade de 35 dias, os quais apresentaram desenvolvimentos precoces considerados pelos valores de $b=0,841$ e $b=0,419$ (ambos $b<1$ ).

Igualmente houve diferença significativa para gordura nos machos (Tabela 2) aos 56 dias $(P=0,03)$ sendo o desenvolvimento considerado tardio $b=4,022$, com crescimento heterogônio. Em estudo de Govaerts et al. (2000) 
REIS, J.S. et al. Desenvolvimento alométrico em uma nova linhagem de codornas para corte. PUBVET, Londrina, V. 6, N. 17, Ed. 204, Art. 1367, 2012.

com frangos de corte machos, o crescimento de peito, coxa, pernas, asa e gordura abdominal foram igualmente considerados tardios $(b>1)$.

Tabela 1 - Equações de alometria para os cortes de carcaça, músculo e osso do peito e perna, respectivamente, em relação ao peso de carcaça fria (PCF), para as idades de abate e respectivos sexos

\begin{tabular}{|c|c|c|c|c|}
\hline Cortes & $\begin{array}{l}\text { Idades } \\
\text { (dias) }\end{array}$ & $\begin{array}{l}\text { Equação } \\
\ln Y=\ln a+b \ln X\end{array}$ & Valor de P & $\begin{array}{l}\text { Teste t } \\
\text { Ho: } b=1\end{array}$ \\
\hline Peito & 35 & $-3,969+1,530$ PCF & 0,15 & NS \\
\hline \multirow{3}{*}{ (machos) } & 42 & $-3,717+1,463$ PCF & 0,52 & NS \\
\hline & 49 & $-0,584+0,872 \mathrm{PCF}$ & 0,81 & NS \\
\hline & 56 & $-4,602+1,635$ PCF & 0,06 & NS \\
\hline \multirow[t]{4}{*}{ (fêmeas) } & 35 & $-0,823+0,926$ PCF & 0,86 & NS \\
\hline & 42 & $-0,853+0,927 \mathrm{PCF}$ & 0,86 & NS \\
\hline & 49 & $-3,794+1,511$ PCF & 0,41 & NS \\
\hline & 56 & $-0,732+0,910$ PCF & 0,68 & NS \\
\hline \multirow{4}{*}{$\begin{array}{l}\text { Osso do peito } \\
\text { (machos) }\end{array}$} & 35 & $6,640-0,841 \mathrm{PCF}$ & 0,05 & $*$ \\
\hline & 42 & $6,362-0,733 P C F$ & 0,33 & NS \\
\hline & 49 & $-9,917+2,397 \mathrm{PCF}$ & 0,54 & NS \\
\hline & 56 & $-4,315+1,309 \mathrm{PCF}$ & 0,79 & NS \\
\hline \multirow[t]{4}{*}{ (fêmeas) } & 35 & $-3,023+1,014 \mathrm{PCF}$ & 0,99 & NS \\
\hline & 42 & $2,705-0,037 P C F$ & 0,42 & NS \\
\hline & 49 & $-3,819+1,208 \mathrm{PCF}$ & 0,82 & NS \\
\hline & 56 & $-4,069+1,258 \mathrm{PCF}$ & 0,65 & NS \\
\hline & 35 & $-7,529+2,079$ PCF & 0,10 & NS \\
\hline \multirow[t]{3}{*}{ (machos) } & 42 & $-2,319+1,056$ PCF & 0,94 & NS \\
\hline & 49 & $0,040+0,603$ PCF & 0,54 & NS \\
\hline & 56 & $-2,827+1,163$ PCF & 0,75 & NS \\
\hline \multirow[t]{4}{*}{ (fêmeas) } & 35 & $-7,249+2,019$ PCF & 0,10 & NS \\
\hline & 42 & $-2,255+1,037$ PCF & 0,91 & NS \\
\hline & 49 & $2,389+0,156 \mathrm{PCF}$ & 0,28 & NS \\
\hline & 56 & $1,513+0,314 \mathrm{PCF}$ & 0,17 & NS \\
\hline \multirow{4}{*}{$\begin{array}{l}\text { Osso da Perna } \\
\text { (machos) }\end{array}$} & 35 & $1,836+0,048 \mathrm{PCF}$ & 0,23 & NS \\
\hline & 42 & $12,994-2,064 \mathrm{PCF}$ & 0,08 & NS \\
\hline & 49 & $-4,464+1,293 \mathrm{PCF}$ & 0,83 & NS \\
\hline & 56 & $-0,943+0,611 \mathrm{PCF}$ & 0,66 & NS \\
\hline \multirow[t]{4}{*}{ (fêmeas) } & 35 & $2,038+0,025 \mathrm{PCF}$ & 0,40 & NS \\
\hline & 42 & $0,836+0,297 P C F$ & 0,19 & NS \\
\hline & 49 & $-3,625+1,136 \mathrm{PCF}$ & 0,90 & NS \\
\hline & 56 & $-5,994+1,591 \mathrm{PCF}$ & 0,57 & NS \\
\hline
\end{tabular}


REIS, J.S. et al. Desenvolvimento alométrico em uma nova linhagem de codornas para corte. PUBVET, Londrina, V. 6, N. 17, Ed. 204, Art. 1367, 2012.

$\mathrm{Na}$ maioria das características observadas não houve diferenças estatisticamente significativas, sendo considerado que 0 valor de $b=1$ e $o$ crescimento denominado isogônico, indicando que as taxas de desenvolvimento das partes em relação ao todo, no caso o peso de carcaça fria, foram semelhantes no intervalo de crescimento considerado.

Não houve efeito significativo $(P<0,05)$ para as fêmeas, ocorrendo crescimento isogônico em todas as variáveis analisadas, diferentemente do ocorrido para os machos, onde ocorreram crescimentos precoces (osso do peito e asas), além de um crescimento tardio (gordura abdominal).

Com a deposição de gordura tardia na carcaça de machos de codornas tipo carne se infere um abate precoce em codornas dessa finalidade, fazendo com que não haja perdas econômicas na produto final dessa ave.

Tabela 2 - Equações de alometria para os cortes de carcaça, asa e gordura, em relação ao peso de carcaça fria (PCF), para as idades de abate e respectivos sexos

\begin{tabular}{|c|c|c|c|c|}
\hline Cortes & $\begin{array}{l}\text { Idades } \\
\text { (dias) }\end{array}$ & $\begin{array}{l}\text { Equação } \\
\ln Y=\ln a+b \ln X\end{array}$ & Valor de $\mathrm{P}$ & $\begin{array}{l}\text { Teste } t \\
\text { Ho: } b=1\end{array}$ \\
\hline Asa & 35 & $0,693+0,419$ PCF & 0,02 & $*$ \\
\hline \multirow[t]{3}{*}{ (machos) } & 42 & $-0,611+0,676$ PCF & 0,61 & NS \\
\hline & 49 & $-8,553+2,200$ PCF & 0,07 & NS \\
\hline & 56 & $-3,911+1,320$ PCF & 0,51 & NS \\
\hline \multirow[t]{4}{*}{ (fêmeas) } & 35 & $0,195+0,517$ PCF & 0,27 & NS \\
\hline & 42 & $-1,444+0,844$ PCF & 0,62 & NS \\
\hline & 49 & $1,874+0,201 \mathrm{PCF}$ & 0,31 & NS \\
\hline & 56 & $-2,972+1,133$ PCF & 0,67 & NS \\
\hline \multirow{4}{*}{$\begin{array}{l}\text { Gordura abdominal } \\
\text { (machos) }\end{array}$} & 35 & $-27,179+5,521 \mathrm{PCF}$ & 0,27 & NS \\
\hline & 42 & $-23,283+4,768 \mathrm{PCF}$ & 0,31 & NS \\
\hline & 49 & $20,682-3,642 P C F$ & 0,17 & NS \\
\hline & 56 & $22,481-4,022 \mathrm{PCF}$ & 0,03 & $*$ \\
\hline \multirow[t]{4}{*}{ (fêmeas) } & 35 & $22,905-4,243 \mathrm{PCF}$ & 0,15 & NS \\
\hline & 42 & $-4,710+1,090 \mathrm{PCF}$ & 0,98 & NS \\
\hline & 49 & $0,490+0,027 P C F$ & 0,88 & NS \\
\hline & 56 & $-19,165+3,868 \mathrm{PCF}$ & 0,29 & NS \\
\hline
\end{tabular}

$*(\mathrm{P}<0,05)$

Possivelmente em outros estudos pudesse ser detectada a possibilidade de diferenças no desenvolvimento das partes em relação ao todo como tem 
REIS, J.S. et al. Desenvolvimento alométrico em uma nova linhagem de codornas para corte. PUBVET, Londrina, V. 6, N. 17, Ed. 204, Art. 1367, 2012.

ocorrido em outras espécies, especialmente ovinos, onde estas diferenças têm sido encontradas (SANTOS et al., 2001).

Igualmente poucas referências bibliográficas foram encontradas para comparar os resultados encontrados com os de outros pesquisadores, pois os estudos em alometria são quase que exclusivamente com outras espécies.

\section{CONCLUSÕES}

No estudo da alometria as taxas de desenvolvimento das partes em relação ao peso de carcaça fria foram semelhantes, nas diversas idades e em ambos os sexos.

Preconiza-se um abate mais precoce em codornas machos do tipo carne, evitando a deposição de gordura, o que acarreta custos desnecessários à produção dessas aves.

\section{AGRADECIMENTOS}

A Coordenação de Aperfeiçoamento de Pessoal de Nível superior (CAPES) pelo financiamento da bolsa de estudos e ao CNPq através do Auxílio Pesquisa/ Processo 474047/2009-1.

\section{REFERÊNCIAS}

ÁVILA, V.S.; OSÓRIO, J.C.S. Efeito do sistema de criação, época de nascimento e ano na velocidade de crescimento de cordeiros. Revista da Sociedade Brasileira de Zootecnia, v.25, n.5, p.1007-1016, 1996.

BERG, R.T.; ANDERSEN, B.B.; LIBORIUSSEN, T. Growth of bovine tissues. 1. Genetic influence on growth patterns muscle, fat and bone in young bull. Animal Production.,26(3):245-258. 1978

BERG, R.T.; BUTTERFIELD, R.M. Muscle: bone ratio and fat percentage as measures of beef carcase composition. Animal Production, v.8, n.1, p.1-11, 1966.

CABRERO, M. Crecimento y característica de La canal de corderos merinos infulencia Del peso de sacrifício, Del sexo y de La incorporación de pulpa de aceituna a La dieta. Córdoba, España.225p. Tese (Doutorado em Produçao Animal) Universidad de Córdoba. 1984. 
FORREST, J.C.; ABERLE, E.D.; HEDRICK, H.B. et al. Fundamentos de la ciencia de la carne. Zaragoza: Acribia. 364p, 1979.

GOVAERTS, T.; ROOM, G.; BUYSE, J. et al. Early and temporary quantitative food restriction of broiler chickens. 2. Effects on allometric growth and growth hormone secretion. British poultry science v.41 p:355-362, 2000.

HUXLEY, J.S. Problems of relative growth. Methuen. London. 276p. 1932

LÓPEZ, M. Calidad de la canal y de la carne en los tipos lechal, ternasco y cordero de la raza Lacha y estudio de su desarrollo. Zaragoza, 1987. Tese (Doutorado em Zoortecnia). Universidad de Zaragoza

MARTINS, R.R.C.; OLIVEIRA, N.M.; OSÓRIO, J.C.S. Efeito da interação genótipo x sistema nutricional sobre a composição regional e tecidual. Ciência Animal Brasileira. v.9, n.1, p. 110-119, 2008.

MURAKAMI, A.E.; GARCIA, L.M.S.; GARCIA, E.R.M. Composição e características organolépticas da carne de codornas. I Simpósio Internacional de Coturnicultura. 2008. Anais... Florianópolis, SC. p 22-31. 2008.

OLIVEIRA, E.G.; ALMEIDA, M.I.M.; MENDES, A.A. et al. Avaliação sensorial de carne de codornas para cortes, abatidas aos 35, 56 e 77 dias de idade, Veterinária e Zootecnia. v.12, n.1/2, 61-68. 2005.

OLIVEIRA, N. M.; OSÓRIO, J. C. S.; MONTEIRO, E.M. Produção de carne em ovinos de cinco genótipos:4. Composição regional e tecidual. Ciência Rural, v. 28,n. 1, p. 125-129, 1998.

OSÓRIO, J.C.S.; OSÓRIO, M.T.M.; OLIVEIRA, N.M. et al. Qualidade, morfologia e avaliação de carcaças. Pelotas: Editora e Gráfica Universitária- UFPEL,195 p, 2002

OSÓRIO, J.C.; SAÑUDO, C.; OSÓRIO, M.T. Produção de carne ovina, alternativa para o Rio Grande do Sul. Pelotas : Editora Universitária/UFPel, 166p, 1998

PEREIRA, J.C.C. Melhoramento genético aplicado à produção animal. 3. ed. Belo Horizonte: FEPMVZ Editora, 555 p, 2001.

ROTA, E.L.; OSÓRIO, M.T.M.; OSÓRIO, J.C.S. Desenvolvimento dos componentes do peso vivo, composição regional e tecidual em cordeiros da raça crioula. Revista Brasileira de Agrociência. v. 8, n. 2, p. 133-137, mai-ago, 2002.

SANTOS, C.L. Estudo do desempenho, das características da carcaça e do crescimento alométrico de cordeiros das raças Santa Inês e Bergamácia. Lavras: Universidade Federal de Lavras, 1999. 142p. Dissertação (Mestrado em Zootecnia) -Universidade Federal de Lavras, 1999.

SANTOS, C.L.; PÉREZ, J.R.O; SIQUEIRA, E.R. Crescimento alompetrico dos Tecidos Ósseo, Muscular e Adiposo na Carcaça de Cordeiros Santa Inês e Bergamácia. Revista brasileira de Zootecnia. V.30 n.2 p.493-498, 2001.

SANTOS, T.A.B.; JORGE, A.M; ANDRIGHETTO, C. Crescimento relativo e composição do ganho de tecidos na carcaça de bubalinos Mediterrâneo jovens abatidos com diferentes pesos. Revista Brasileira de Zootecnia, v. 38, n.2, p.361-365, 2009. 
SANTOS, C.L.; PÉREZ, J.R.O; SIQUEIRA, E.R. Crescimento alométrico dos Tecidos Ósseo, Muscular e Adiposo na Carcaça de Cordeiros Santa Inês e Bergamácia. Revista Brasileira de Zootecnia, v.30 n.2 p.493-498, 2001.

SAÑUDO, C. Calidad d ela canal y de la carne en El ternasco aragonés. Zaragoza, 1980. 337p. Tese (Doutorado em Zootecnia) Universidade de Zaragoza.

SAS - INSTITUTE. User's guide: statistics. Cary, NC 2008.

SOUSA, M.B.S; OLIVEIRA, M.C.O; FRANSCISCO, M.S. Avaliação sensorial de almôndegas produzidas com carne de codorna mecanicamente separada e diferentes concentrações de proteínas texturizada de soja. III JORNADA NACIONAL DA AGROINDUSTRIA. Anais... Bananeiras, 2008 